
leira 24: $295-300$

\title{
Produção hidropônica de alface em solução nutritiva com e sem silício
}

\author{
José Magno Q Luz; Silése T M R Guimarães; Gaspar Henrique Korndörfer
}

${ }^{1}$ UFU-Instituto de Ciências Agrárias, C. Postal 593, 38400-783 Uberlândia-MG; jmagno@umuarama.ufu.br

\section{RESUMO}

Avaliou-se o efeito do silício sobre o desempenho de nove cultivares de alface cultivadas em solução nutritiva no sistema hidropônico NFT. O experimento foi conduzido em ambiente protegido, durante os meses de março a maio de 2003. O delineamento experimental foi o de blocos casualizados em esquema fatorial 9x2, com três repetições, com os fatores: nove cultivares de alface (Vera, Verônica, Elisa, Regina, Aurélia, Tainá, Lucy Brown, Uberlândia10000 e Mimosa Salad Bowl); e duas soluções nutritivas, uma contendo silício - $1,5 \mathrm{mmol} \mathrm{L}^{-1} \mathrm{e}$ outra sem silício. A fonte de silício utilizada foi a sílica gel de origem japonesa, com $20 \%$ de $\mathrm{SiO}_{2}$ e $80 \%$ de $\mathrm{H}_{2} \mathrm{O}$. As características analisadas foram: diâmetro da cabeça, massa seca e fresca de parte aérea e de raiz e, concentração de silício nas folhas e raízes. As plantas de alface que receberam silício apresentaram um menor tamanho quando comparadas às plantas cultivadas em solução sem silício, apesar de, em ambos os casos, terem alcançado tamanho comercial. As plantas tratadas com silício apresentaram menor incidência da anomalia fisiológica queima dos bordos. Dessa forma o silício pode ser uma alternativa viável para produção hidropônica de alface, principalmente quando se leva em consideração as novas tendências de mercado por produtos menores e com boa aparência.

Palavras-chave: Lactuca sativa, sílica gel, nutrição de plantas, hidroponia.

\section{ABSTRACT \\ Hidroponic production of lettuce in hidroponic solution with or without silicon}

The effect of silicon was evaluated on the performance of nine lettuce cvs, cultivated in the nutritive solution in hidroponic system NFT. The experiment was conducted in protected cultivation, from March to May 2003. The randomized complete blocks design 9x2 was used, with three replications. Two factors were studied: nine lettuce cultivar (Vera, Verônica, Elisa, Regina, Aurélia, Tainá, Lucy Brown, Uberlândia-10000 and Mimosa), and presence $\left(1,5 \mathrm{mmol} \mathrm{L}^{-1}\right)$ or absence of silicon (japanese "silica gel") in the nutritive solution with $20 \%$ of $\mathrm{SiO}_{2}$ and $80 \%$ of $\mathrm{H}_{2} \mathrm{O}$. The head diameter, weight of dry and fresh matter of head and roots, the concentration of silicon in leaves and roots were analyzed. The lettuce plants which received silicon presented a lower weight in comparison to the ones cultivated in solution without silicon, although both reached commercial weight. The lettuce treated with silicon presented lower incidence of physiological anomalies such as tip burn. Therefore, the silicon may be a reliable alternative for hydroponics production of lettuce mainly when considering the new market tendencies for products with better appearance.

Keywords: Lactuca sativa, gel silica, plant nutrition, hydroponics.

\section{(Recebido para publicação em 22 de agosto de 2005; aceito em 30 de agosto de 2006)}

$\mathrm{O}$ cultivo hidropônico de plantas no Brasil tem crescido nos últimos anos. No entanto, a sua técnica é pouco conhecida por parte dos agricultores tradicionais, o que gera apreensão e insegurança em adotar este sistema de produção. Porém, buscando atender a um mercado cada vez mais exigente em qualidade, a hidroponia se apresenta como uma técnica bastante promissora, devido as suas principais vantagens: controle no uso de nutrientes; antecipação da colheita; homogeneidade de oferta e qualidade dos produtos durante todo o ano; ausência de necessidades de rotação de culturas, permitindo ao produtor um altíssimo nível de especialização; menor incidência de pragas e doenças; menor utilização de mão-de-obra e racionalização do uso da energia. As desvantagens deste sistema são: custo inicial de implantação elevado, exige alto grau de tecnologia e acompanhamento permanente do sistema, dependência de energia elétrica ou de sistema alternativo, e a fácil disseminação de patógenos através da própria solução nutritiva (Faquim \& Furlani, 1999).

A alface (Lactuca sativa L.), é considerada a hortaliça folhosa mais importante na alimentação do brasileiro e, juntamente com o tomate é a hortaliça preferida para as saladas por ser refrescante, de sabor agradável e de fácil preparo, o que assegura à cultura expressiva importância econômica. No Brasil são plantados seis grupos de cultivares de alface, sendo: grupo Americana com folhas que formam uma cabeça, semelhante ao repolho, com os bordos das folhas crespas (ex.: cultivares Tainá e Lucy Brown); Repolhuda-Manteiga, semelhante ao anterior, mas com os bordos das folhas lisas (ex.: cultivares Elisa e Aurélia); grupo Solta-Lisa que são alfaces que não formam uma cabeça e possuem os bordos das folhas lisas (ex.: cultivares Regina e Uberlândia-10000);
Solta-Crespa que são alfaces semelhantes ao grupo anterior, mas possuem os bordos das folhas crespas (ex.: cultivares Vera e Verônica)- é o que mais cresceu o plantio no Brasil, correspondendo hoje a $70 \%$ do mercado; existem ainda o grupo Mimosa, que são alfaces com folhas bem recortadas (ex.: cultivar Salad Bowl) e o grupo Romana, sendo estes dois últimos com menor importância econômica (Filgueira, 2003).

Recentemente, tem crescido o cultivo desta hortaliça em sistema hidropônico no Brasil, principalmente de cultivares do grupo Solta-Crespa. Esta técnica está sendo utilizada pelos produtores como forma da agregação de valor ao produto e viabilização do negócio (Costa \& Junqueira, 2000). Segundo Bliska Jr. \& Honório (1995), a hidroponia reduz em cerca de dez dias o período de colheita da alface, devido à possibilidade do perfeito controle das condições de umidade e temperatura dentro da estufa. 
Ainda podem ser citadas as reduções no uso de agrotóxicos, quando comparados com o cultivo tradicional, a possibilidade de um excelente plano de escalonamento de produção e uma melhor padronização dos produtos.

Um aspecto fundamental para o cultivo hidropônico é a escolha da solução nutritiva, que deve ser formulada de acordo com o requerimento nutricional da espécie que se deseja produzir, ou seja, todos os elementos essenciais para o seu crescimento em proporções adequadas. No entanto são poucas as informações sobre a melhor solução. Alternativas de novas formulações vêm sendo estudadas, inclusive com silício, que demonstra um potencial na redução de doenças e anomalias fisiológicas como, por exemplo, queima dos bordos em alface. Korndorfer et al. (2002) demonstraram que o silício é capaz de aumentar a resistência das plantas aos ataques de insetos, nematóides, bactérias e fungos na melhoria do estado nutricional, na redução da transpiração e possivelmente também em alguns aspectos da eficiência fotossintética (Korndorfer $e t$ al., 2002). Em alface, a sílica solúvel como fonte de silício, tem sido pouco estudada, entretanto inúmeros trabalhos têm demonstrado o efeito benéfico da sua utilização em diversas outras culturas (Barbosa Filho et al., 2001). Voogt \& Sonneveld (2001), usando silício em solução nutritiva com e sem silício no cultivo de alface, verificaram que a presença de silício diminuiu significativamente os sintomas de toxidez de manganês, que se caracteriza por manchas escuras nas margens das folhas mais velhas da alface. No entanto, os autores verificaram que a absorção de Si na alface foi pequena, e o conteúdo de Si nas plantas que receberam o tratamento foi pouco maior em comparação as do tratamento sem $\mathrm{Si}$.

Em alface as doenças de maior incidência em hidroponia são míldio (Bremia lactuca), podridão de raízes por Pythium, podridão por esclerotínia (Sclerotinia sclerotiorum), septoriose (Septoria lactucae) e o vírus vira-cabeça, transmitido por tripes. Estas doenças podem ser atenuadas por uma série e medidas de caráter preventivo, tais como: utilização de sementes sadias, limpeza e desinfecção do sistema hidropônico, e fertilização com solução nutritiva adequada, e nesta última medida é que o silício pode ser benéfico. Vale ressaltar que as principais cultivares plantadas, incluindo as utilizadas neste trabalho, não possuem resistência para as estas doenças, bem como para o distúrbio fisiológico queima dos bordos.

O objetivo deste trabalho foi avaliar o efeito do silício sobre o desempenho de nove cultivares de alface cultivadas em solução nutritiva no sistema hidropônico NFT (Nutrient Film Technique).

\section{MATERIAL E MÉTODOS}

O experimento foi conduzido na Universidade Federal de Uberlândia, Campus Umuarama, durante os meses de março a maio de 2003, em estufa tipo túnel alto, em 2 bancadas de cultivo com $8,75 \mathrm{~m}$ de comprimento cada uma, com nove perfis médios de polipropileno (100 $\mathrm{mm}$ ) para cultivo hidropônico com espaçamento de $18 \mathrm{~cm}$ entre perfis e $25 \mathrm{~cm}$ entre orifícios. Cada perfil foi abastecido por um reservatório plástico de 1000 litros ao qual foi conectado uma bomba de $1 \mathrm{CV}$. Os reservatórios estavam enterrados com o objetivo de evitar o aquecimento da solução nutritiva. $\mathrm{O}$ sistema hidropônico adotado foi o NFT.

$\mathrm{O}$ delineamento experimental foi o de blocos casualizados em esquema fatorial 9x2, com três repetições, sendo nove cultivares de alface (Vera, Verônica, Elisa, Regina, Aurélia, Tainá, Lucy Brown, Uberlândia-10000 ou UDIA 10000 e Mimosa Salad Bowl) e duas soluções nutritivas, sendo uma contendo silício - 1,5 mmol L-1 e outra sem silício. A fonte de silício utilizada foi a sílica gel de origem japonesa com 20\% de $\mathrm{SiO}_{2}$ e $80 \%$ de $\mathrm{H}_{2} \mathrm{O}$, e a solução nutritiva foi a proposta por Furlani et al. (1999). Os blocos foram dispostos de acordo com a posição da planta no perfil hidropônico (posição superior - entrada do perfil, posição mediana e posição inferior - saída do perfil). A parcela foi composta por 11 plantas em cada canal, na posição superior (bloco I) e por 12 plantas em cada canal na posição mediana (bloco II) e inferior (bloco III).

Para o desenvolvimento das mudas de alface foram utilizadas placas de es- puma fenólica com dimensões de $2,5 \times 2,5 \times 3,0 \mathrm{~cm}$ por célula, que foram enxaguadas com água corrente, com o objetivo de eliminar possíveis compostos ácidos remanescentes de sua fabricação. Metade das placas foram umedecidas com solução nutritiva, diluída em $50 \%$ e a outra metade com a mesma solução nutritiva mais $1,5 \mathrm{mmol}$ $\mathrm{L}^{-1}$ de silício. As mudas foram mantidas em uma estrutura coberta com tela de $50 \%$ de sombreamento por 18 dias. Em seguida as plântulas obtidas foram transferidas para duas bancadas de desenvolvimento (berçário) que continha quinze perfis de polipropileno pequeno (50 mm) espaçadas de $10 \mathrm{~cm}$ entre si e com $10 \mathrm{~cm}$ entre orifícios. Em uma bancada ficaram as plântulas que recebiam solução nutritiva diluída em $50 \%$ com silício, e passaram a receber a solução não mais diluída, mas também com silício (sílica gel 1,5 $\mathrm{mmol} \mathrm{L}^{-1}$ de silício), e na outra bancada ficaram as plântulas que recebiam solução nutritiva diluída em 50\% sem silício, e passaram a receber a solução não mais diluída, também sem silício.

A circulação da solução nutritiva nos perfis foi controlada por um temporizador "timer" programado para durante o dia (de $6 \mathrm{~h}$ às $18 \mathrm{~h}$ ) permanecer ligado 15 min e desligado $15 \mathrm{~min}$, e às $24 \mathrm{~h}$ era ligado por $15 \mathrm{~min}$, com um fluxo de solução de 1,0 litro por min.

As mudas permaneceram no berçário por um período de 12 dias, sendo então transferidas para duas bancadas de crescimento e submetidas à irrigação com a mesma solução nutritiva, com ou sem silício, sob o mesmo regime de circulação da solução. Foi feito sorteio para cada variedade no momento da transferência para o perfil de crescimento em relação às posições: inicial, mediana e final do perfil.

A solução nutritiva foi preparada a partir da água da rede urbana (Departamento Municipal de Águas e Esgotos de Uberlândia - DMAE), a qual foi analisada pelo Instituto de Química da Universidade Federal de Uberlândia - UFU, estando de acordo com as especificações de Martinez (1997). Este recomenda que ao se usar água da rede urbana, é conveniente deixá-la em repouso por cerca de 24 horas para eliminação do cloro 
usado em seu tratamento. Para tanto foi instalado um reservatório com capacidade de 1000 litros.

Para o preparo de 1000 litros da solução nutritiva proposta por Furlani et al. (1999), foi utilizado um kit comercial para hidroponia, denominado kit básico (Tabela 1). Todos os reagentes com exceção das fontes de micronutrientes, que já vêm na forma líquida pronta para o uso, foram dissolvidos separadamente em um balde, antes de serem adicionados ao reservatório de 1000 L. Esse cuidado foi tomado para se evitar uma reação prévia entres os reagentes, que poderia ocasionar a formação de precipitados. No momento da transferência das plantas para os perfis de $100 \mathrm{~mm}$, foram ajustados a condutividade elétrica (CE) e o pH das duas soluções.

O manejo da solução nutritiva foi realizado diariamente através da reposição da água consumida; do acompanhamento da condutividade elétrica, que foi mantida em uma faixa de 1,8 a 2,0 $\mathrm{mS} \mathrm{cm} \mathrm{cm}^{-1}$ e da correção do $\mathrm{pH}$, que foi realizada diariamente com uma solução de $\mathrm{NaOH} 1 \mathrm{~mol} \mathrm{~L}^{-1}$ e HCL $10 \%$, mantendo-o entre 5,5 a 6,5. O ajuste da CE foi efetuado todas as vezes que esta baixasse de $25 \%$ em relação a CE inicial, ou seja todas as vezes que a CE diminuísse $0,25 \mathrm{mS} \mathrm{cm}^{-1}$ era adicionado a mesma 1 L da solução A e 1 L da solução B, e uma vez por semana se adicionava 50 $\mathrm{ml} / 1000$ da solução C (micronutrientes), soluções estas propostas por Furlani et al. (1999) (Tabela 2).

Quando todas as plantas atingiram o tamanho comercial, foi feita a colheita das duas plantas centrais de cada parcela e avaliação das características: diâmetro da cabeça, massa fresca da parte aérea e de raiz e, teores de silício nas folhas e raízes.

Em seguida as medições das massas frescas e do diâmetro da cabeça, as plantas foram submetidas a uma pré-secagem dentro da casa de vegetação por 24 horas (ponto de murcha) e a uma secagem em estufa a $65^{\circ} \mathrm{C}$ até atingir massa constante para avaliação das massas secas de raiz e de parte aérea, o que ocorreu após 72 horas de secagem.

Após a avaliação das massas secas, essas amostras foram moídas para a rea-

Tabela 1. Quantidade de sais para o preparo de 1000 litros de solução nutritiva (Furlani et al., 1999) UFU, Uberlândia, 2004.

\begin{tabular}{lc}
\hline Sal ou fertilizante & $\mathbf{g} / \mathbf{1 0 0 0 \mathrm { L }}$ \\
\hline Nitrato de cálcio hydro Especial & 750,0 \\
Nitrato de potássio & 500,0 \\
Fosfato monoamônio (MAP) & 150,0 \\
Sulfato de magnésio & 400,0 \\
Sulfato de cobre & 0,15 \\
Sulfato de zinco & 0,50 \\
Sulfato de manganês & 1,50 \\
Ácido bórico, ou & 1,50 \\
Bórax & 2,30 \\
Molibdato de sódio (Na $\left.{ }_{2} \mathrm{MoO}_{4} 2 \mathrm{H}_{2} \mathrm{O}\right)$, ou & 0,15 \\
Molibdato de amônio & 0,15 \\
Tenso-Fe ${ }^{(F e E D D H M A-6 \% ~ F e .) ~ o u ~}$ & 30,0 \\
Dissolvine ${ }^{\circledR}$ (FeEDTA-13\% Fe.) ou & 13,8 \\
Ferrilene ${ }^{(F e E D D H A-6 \% ~ F e .) ~ o u ~}$ & 30,0 \\
FeEDTANa ${ }_{2}$ (10mg/mL de Fe.) & $180,0 \mathrm{~mL}$ \\
\hline
\end{tabular}

Tabela 2. Composição de sais das soluções de ajuste para as culturas de hortaliças de folhas (Furlani et al., 1999). UFU, Uberlândia, 2004.

\begin{tabular}{|c|c|c|}
\hline Solução & Sal ou fertilizante & Quantidade $\left({\left.\mathrm{g} 10 \mathrm{~L}^{-1}\right)}^{-1}\right.$ \\
\hline \multirow{3}{*}{ A } & Nitrato de potássio & $1.200,0$ \\
\hline & Fosfato monoamônio purificado & 200,0 \\
\hline & Sulfato de magnésio & 240,0 \\
\hline$B$ & Nitrato de Cálcio Hydro especial & 600,0 \\
\hline \multirow{6}{*}{ C } & Sulfato de cobre & 1,0 \\
\hline & Sulfato de zinco & 2,0 \\
\hline & Sulfato de manganês & 10,0 \\
\hline & Ácido Bórico & 5,0 \\
\hline & Molibdato de sódio & 1,0 \\
\hline & FeEDTANa2(10 mg mL-1 de Fe) & $120,0 \mathrm{~mL}$ \\
\hline
\end{tabular}

lização da análise de silício nas folhas e raízes. Utilizou-se a metodologia de Elliot \& Snyder (1991) adaptada. Foram pesados $0,100 \mathrm{~g}$ de cada amostra, colocados em tubos de polietileno $(100 \mathrm{~mL})$ previamente enxaguados com $\mathrm{NaOH} 0,1 \mathrm{~mol} \mathrm{~L}^{-1}$ e água destilada, onde foram adicionados $2 \mathrm{~mL}$ de $\mathrm{H}_{2} \mathrm{O}_{2} 50 \%$ e levemente agitados por alguns minutos em um vibrador e $3 \mathrm{~mL}$ de $\mathrm{NaOH} 50 \%$ seguindo o mesmo procedimento. Após essa etapa, os tubos foram colocados em banho-maria durante uma hora, agitando-os periodicamente durante os trinta primeiros min. Após este procedimento, os tubos foram individualmente cobertos com copos plásticos e, posteriormente, levados à autoclave com 138 KPa por uma hora. Completado este período, os tubos foram removidos $\mathrm{e}$ acrescidos de $45 \mathrm{~mL}$ de água destilada.
As amostras foram deixadas em repouso por 12 horas e, em seguida foi separada uma alíquota de $1 \mathrm{~mL}$ do sobrenadante do extrato, colocado em copo plástico, de volume de $50 \mathrm{~mL}$, acrescentando-se $15 \mathrm{ml}$ de água destilada. Foram adicionados às amostras, rapidamente, os seguintes reagentes: 1 $\mathrm{ml}$ de $\mathrm{HCl}(1: 1$ ou $50 \%)+2 \mathrm{ml} \mathrm{de}$ molibdato de amônio. A cor amarela apareceu em todas as amostras contendo silício. Depois de 5 a $10 \mathrm{~min}$, foram adicionados $2 \mathrm{ml}$ de ácido oxálico (50\%). Ao mesmo tempo, foram preparadas curvas padrões, com concentrações diferentes de silício. A determinação do silício foi realizada em um colorímetro com comprimento de onda de $410 \mathrm{~nm}$ após um intervalo de $2 \mathrm{~min}$. A cor amarela é pouco estável, permanecendo assim por apenas $15 \mathrm{~min}$. 
Tabela 3. Diâmetro de parte aérea, massa fresca de parte aérea e raiz (MFPA, MFRA), massa seca de parte aérea e raiz (MSPA, MSRA) e porcentagem de silício na raiz ( $\mathrm{Si}$ RA) de cultivares de alface cultivadas no sistema hidropônico em solução nutritiva com e sem silício. UFU, Uberlândia, 2004.

\begin{tabular}{|c|c|c|c|c|c|c|}
\hline \multirow{2}{*}{ Tratamentos } & \multirow{2}{*}{ Diam. $(\mathrm{cm})$} & MFPA & MFRA & MSPA & MSRA & \multirow{2}{*}{ Si RA (\%) } \\
\hline & & \multicolumn{4}{|c|}{$\left(\right.$ g planta $\left.^{-1}\right)$} & \\
\hline Sem Si & $28,02 \mathrm{a}$ & $287,81 \mathrm{a}$ & $44,84 \mathrm{a}$ & $11,95 \mathrm{a}$ & $1,57 \mathrm{a}$ & $0,66 \mathrm{a}$ \\
\hline com Si & $26,55 \mathrm{~b}$ & $226,52 b$ & $36,66 \mathrm{~b}$ & $9,91 \mathrm{~b}$ & $1,37 \mathrm{~b}$ & $0,66 \mathrm{a}$ \\
\hline C.V.(\%) & 3,71 & 7,67 & 5,70 & 7,53 & 5,75 & 15,48 \\
\hline
\end{tabular}

Medias seguidas por letras iguais, na coluna, não diferem entre si no nível de 5\% de significância pelo teste de Tukey.

Tabela 4. Diâmetro de cabeça, massa fresca de parte aérea e raiz (MFPA, MFRA), massa seca de parte aérea e raiz (MSPA, MSRA) e porcentagem de Silício na raiz (Si RA) em cultivares de alface cultivadas no sistema hidropônico, em solução nutritiva com e sem silício. UFU, Uberlândia, 2004.

\begin{tabular}{llccccc}
\hline \multirow{2}{*}{ Cultivares } & \multirow{2}{*}{ Diam. (cm) } & MFPA & \multicolumn{7}{c}{ MFRA } & MSPA & MSRA & \multirow{2}{*}{ Si RA (\%) } \\
\cline { 3 - 7 } & & \multicolumn{5}{c}{ (g planta- $^{-1}$ ) } \\
LucyBrown & $23,14 \mathrm{c}$ & $452,33 \mathrm{a}$ & $38,10 \mathrm{a}$ & $14,63 \mathrm{ab}$ & $1,42 \mathrm{ab}$ & $0,63 \mathrm{ab}$ \\
Tainá & $22,98 \mathrm{c}$ & $410,69 \mathrm{a}$ & $35,61 \mathrm{a}$ & $13,88 \mathrm{ab}$ & $1,32 \mathrm{ab}$ & $0,77 \mathrm{a}$ \\
Elisa & $24,91 \mathrm{bc}$ & $163,82 \mathrm{c}$ & $34,44 \mathrm{a}$ & $7,78 \mathrm{c}$ & $1,14 \mathrm{~b}$ & $0,75 \mathrm{a}$ \\
Regina & $25,53 \mathrm{abc}$ & $176,66 \mathrm{c}$ & $37,71 \mathrm{a}$ & $7,65 \mathrm{c}$ & $1,20 \mathrm{~b}$ & $0,68 \mathrm{ab}$ \\
Vera & $28,13 \mathrm{abc}$ & $238,40 \mathrm{bc}$ & $37,89 \mathrm{a}$ & $10,62 \mathrm{bc}$ & $1,33 \mathrm{ab}$ & $0,70 \mathrm{ab}$ \\
Verônica & $30,09 \mathrm{ab}$ & $214,81 \mathrm{c}$ & $40,21 \mathrm{a}$ & $9,63 \mathrm{bc}$ & $1,31 \mathrm{ab}$ & $0,68 \mathrm{ab}$ \\
Aurélia & $29,53 \mathrm{abc}$ & $341,49 \mathrm{ab}$ & $58,53 \mathrm{a}$ & $16,95 \mathrm{a}$ & $2,50 \mathrm{a}$ & $0,46 \mathrm{~b}$ \\
UDIA 10000 & $30,12 \mathrm{ab}$ & $223,35 \mathrm{bc}$ & $42,40 \mathrm{a}$ & $10,79 \mathrm{bc}$ & $1,65 \mathrm{ab}$ & $0,53 \mathrm{ab}$ \\
Mimosa & $31,92 \mathrm{a}$ & $166,96 \mathrm{c}$ & $43,17 \mathrm{a}$ & $8,05 \mathrm{c}$ & $1,45 \mathrm{ab}$ & $0,51 \mathrm{ab}$ \\
\hline C.V. (\%) & 4,23 & 7,69 & 6,41 & 8,09 & 9,84 & 14,59 \\
\hline
\end{tabular}

Medias seguidas por letras distintas, na coluna, diferem entre si, no nível de 5\% de significância, pelo teste de Tukey.

Os dados obtidos em todas as variáveis foram avaliados com auxílio do programa estatístico SANEST (Zonta \& Machado, 1984).

\section{RESULTADOS E DISCUSSÃO}

As plantas de alface cultivadas em solução nutritiva com silício apresentaram menor diâmetro de parte aérea, menor massa fresca e seca de parte aérea e de raiz não diferindo, no entanto, da solução sem silício para a porcentagem de silício na raiz (Tabela 3). Provavelmente o silício interfira na absorção de algum dos nutrientes essenciais para a alface. A adição de silício para plantas de arroz cultivadas em solução nutritiva diminuiu os teores de boro e fósforo nas raízes, de boro, cálcio, ferro e manganês na casca (Silva \& Bohnen, 2001).

O Si acumulado nas células epidérmicas e nas paredes dos estômatos encontra-se na forma de $\mathrm{H}_{4} \mathrm{SiO}_{4}$ (ácido monosilícico). Quando a planta começa a perder água (estresse hídrico) a forma monomérica se transforma e formas poliméricas, isto é o Si começa a formar cadeiras mais pesadas de ácido polisilícico. O Si ao se polimerizar, diminui a flexibilidade das paredes dos estômatos e a tendência é de permanecerem fechados. Com os estômatos fechados, a transpiração diminui e a perda de água também. Nestas circunstâncias, segundo Faria (2000) a fotossíntese diminui, e isto pode ter levado ao menor desenvolvimento e conseqüente menor massa das plantas de alface cultivadas na solução com silício, principalmente considerando as altas temperaturas registradas durante o experimento, pois as médias de temperatura máxima e mínima, nos meses de março, abril e maio, variaram de $36,5^{\circ} \mathrm{C}$ e $23,5^{\circ} \mathrm{C}$; $35^{\circ} \mathrm{C}$ e $19^{\circ} \mathrm{C} ; 36^{\circ} \mathrm{C}$ e $17^{\circ} \mathrm{C}$, respectivamente, tendo sido comum a temperatura atingir os $40^{\circ} \mathrm{C}$ nas horas mais quentes do dia.
Com relação a variável diâmetro de parte aérea a cultivar que apresentou maior diâmetro foi a Mimosa não diferindo estatisticamente, no entanto dos demais grupos de alface de folhas soltas (Tabela 4). Já as cultivares do grupo americana (Lucy Brown e Tainá) apresentaram diâmetro de parte aérea menor. Esses resultados já eram esperados, pois o espaçamento entre perfis e entre plantas foram inferiores ao recomendado a essas cultivares. No entanto, o menor diâmetro médio não significa que estas cultivares tinham tamanho e aparência não comerciais. Vale ressaltar que, na prática, as estufas hidropônicas são confeccionadas para plantios mais adensados de maneira a se ter o maior número de plantas possíveis e conseqüente maior produção, justificando o alto investimento destas estruturas.

As cultivares que apresentaram maior massa fresca e seca de parte aérea foram as do grupo americanas (Lucy Brown e Tainá) não diferindo da cultivar Aurélia que é do grupo cabeça manteiga (Tabela 4). Essa superioridade pode ser explicada pelas características agronômicas destas cultivares, ou seja, são cultivares que apresentam um grande número de folhas em relação às cultivares que não formam cabeça.

Todas as cultivares tiveram um bom desempenho em relação à massa fresca de raiz não havendo nenhuma diferença estatística entre elas (Tabela 4). Já para massa seca de raiz foram observadas diferenças estatísticas sendo as cultivares Aurélia, Lucy Brown, Tainá, Vera, Verônica, UDIA 10000 e Mimosa as que apresentaram maiores valores, porém não diferindo significativamente entre si.

As cultivares Tainá e Elisa apresentaram as maiores porcentagens de silício nas raízes com 0,77 e $0,75 \%$ de silício respectivamente, no entanto só diferiram estatisticamente da cultivar Aurélia (Tabela 4). Resultados semelhantes foram encontrados por Voogt \& Sonneveld (2001), que trabalhando com alface no sistema NFT, verificaram que, apesar do claro efeito do acréscimo de $\mathrm{Si}$ na redução da toxidade de $\mathrm{Mn}$, a absorção de Si na alface era pequena, e o conteúdo de Si nas plantas que receberam o tratamento era levemente maior em com- 
paração as do tratamento zero de Si.

Houve interação significativa entre os fatores cultivar e dose de silício para a variável silício na parte aérea. Na solução nutritiva com silício a cultivar que apresentou maior acúmulo deste elemento na parte aérea foi a UDIA 10000 com $0,33 \%$ não diferindo estatisticamente das cultivares Mimosa e Verônica. Na solução nutriiva sem silício, a cultivar UDIA 10000 também apresentou significativamente maior acúmulo com $0,30 \%$ deste elemento em relação às todas as outras cultivares (Tabela 5). As plantas cultivadas na solução sem silício, apesar de conter esse elemento em sua composição, apresentaram valores menores. A presença de silício nestas plantas pode ser explicada pelo fato do silício ser um elemento muito abundante na natureza, estando assim presente em toda parte, inclusive na água. No entanto, não há como confirmar esta hipótese, pois não foi medida a quantidade de silício na água usada no experimento.

As cultivares de alface Tainá, Lucy Brown, UDIA 10000 e Aurélia apresentaram sintomas de queima dos bordos sendo estes em maior proporção nas plantas cultivadas em solução nutritiva sem acréscimo de silício (Figura 1). Essas cultivares são suscetíveis a esse distúrbio fisiológico que está relacionado à desestruturação da parede celular, às altas temperaturas do ar, a deficiência de $\mathrm{Ca}$ e a altas concentrações salinas do meio (Fontes, 2003). O efeito benéfico do silício na diminuição de queima dos bordos está de certa forma, de acordo com Voogt \& Sonneveld (2001), que trabalhando com alface também observaram uma diminuição dos sintomas de manchas escuras nos bordos das folhas mais velhas, no entanto, segundo os autores, foi devido à toxidez de manganês.

O silício tem um importante papel na estruturação das plantas. Sua presença na parede celular pode elevar os conteúdos de hemicelulose e lignina, aumentando a rigidez da célula (Barbosa Filho et al., 2001). Além disso, o Si regula a transpiração e se a planta perde menos água, logo a possibilidade de necrose dos tecidos e conseqüente queima dos bordos, por falta de água é menor.
Tabela 5. Interação entre as nove cultivares e as duas soluções nutritivas, com e sem silício, para a característica percentagem de silício na parte aérea em cultivares de alface em sistema hidropônico. UFU, Uberlândia, 2004.

\begin{tabular}{lcc}
\hline \multirow{2}{*}{ Cultivares } & \multicolumn{2}{c}{ Solução nutritiva } \\
\cline { 2 - 3 } UDIA 10000 & Com silício & Sem silício \\
Mimosa & $0,33 \mathrm{Aa}$ & $0,30 \mathrm{Aa}$ \\
Lucy Brown & $0,24 \mathrm{Aab}$ & $0,13 \mathrm{Bbc}$ \\
Aurélia & $0,18 \mathrm{Abc}$ & $0,03 \mathrm{Bd}$ \\
Elisa & $0,18 \mathrm{Abc}$ & $0,13 \mathrm{Abc}$ \\
Regina & $0,13 \mathrm{Abc}$ & $0,06 \mathrm{Bcd}$ \\
Vera & $0,13 \mathrm{Abc}$ & $0,12 \mathrm{Abc}$ \\
Verônica & $0,10 \mathrm{Ac}$ & $0,08 \mathrm{Acd}$ \\
Tainá & $0,22 \mathrm{Aab}$ & $0,13 \mathrm{Bbc}$ \\
\hline C.V. (\%) & $0,10 \mathrm{Ac}$ & $0,03 \mathrm{Bd}$ \\
\hline
\end{tabular}

Médias seguidas pelas mesmas letras maiúsculas, na linha, e pelas mesmas letras minúsculas, na coluna, não diferem entre si no nível de 5\% de significância pelo teste de Tukey.

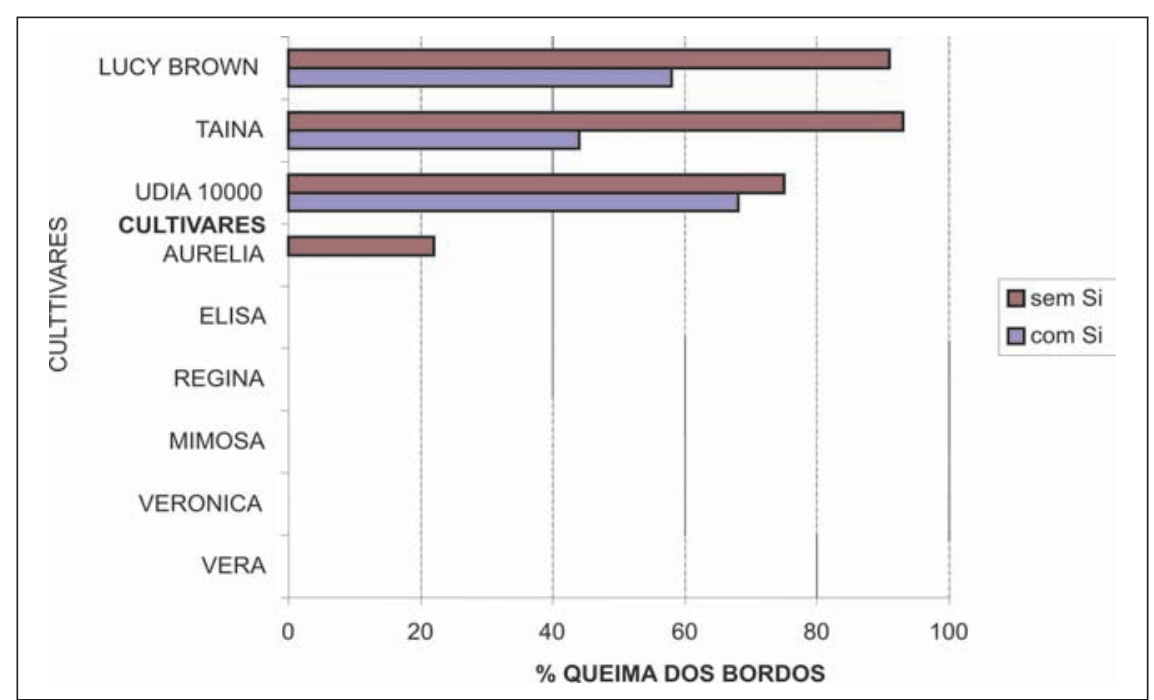

Figura 1. Representação gráfica da incidência da queima dos bordos em cultivares de alface produzida no sistema hidropônico em solução nutritiva com e sem silício. UFU, Uberlândia, 2004.

Como as plantas de alface cultivadas em solução com silício apresentaram menores problemas com anomalias fisiológicas do tipo queima dos bordos, o silício pode ser uma alternativa viável para produção hidropônica de alface, principalmente quando se leva em consideração um mercado consumidor mais exigente por produtos com ótima aparência.

\section{REFERÊNCIAS}

BARBOSA FILHO MP; SNYDER GH; FAGERIA NK; DATNOFF L; SILVA OF. 2001. Silicato de cálcio como fonte de silício para arroz de sequeiro. Revista Brasileira de Ciência do Solo 25: 325-330.
BLISKA JUNIOR A; HONÓRIO SL. 1995. Cartilha tecnológica de hidroponia. Campinas: UNICAMP. $24 \mathrm{p}$.

COSTA JS; JUNQUEIRA AMR. 2000. Diagnóstico do cultivo hidropônico de hortaliças na região do Distrito Federal.Horticultura Brasileira 18: 49-52.

ELLIOTT CT; SNYDER GH. 1991. Autoclaveinduced digeston for colorimetric determination of silicon in rice straw. Journal Agronomic Food Chem 39: 1118-1119.

FAQUIM V; FURLANI PR. 1999. Cultivo de hortaliças de folhas em hidroponia em ambiente protegido. Informe Agropecuário 200/ 201: 99-104.

FARIA RJ. 2000. Influência do silicato de cálcio na tolerância do arroz de sequeiro ao déficit hídrico do solo. Lavras: UFLA. 47p. (Tese de mestrado).

FILGUEIRA FAR. 2003. Novo Manual de Olericultura: Agrotecnologia moderna na produção e comercialização de hortaliças. $2^{\mathrm{a}}$ ed. Viçosa: UFV. 412p. 
FONTES PCR. 2003. Podridão apical do tomate, queima dos bordos das folhas de alface e depressão amarga dos frutos em maçã: deficiência de Ca? Horticultura Brasileira 21: 144.

FURLANI PR; SILVEIRA LCP; BOLONHEZI D; FAQUIM V. 1999. Cultivo hidropônico de plantas. Campinas: IAC. 52p. (Boletim técnico, 180).

KORNDORFER GH; PEREIRA HS CAMARGO MS. 2002. Silicato de cálcio e magnésio na agricultura. Uberlândia: UFU. 23p. (Boletim técnico, 01).
MARTINEZ HEP. 1997. Formulação de soluções nutritivas para cultivos hidropônicos comerciais. Jaboticabal: FUNEP. 31p.

SILVA LS; BOHNEN H. 2001. Rendimento e acúmulo de nutrientes pelo arroz em solução nutritiva com e sem a adição de silício. Revista Brasileira de Ciência do Solo 25: 771-777.
VOOGT W; SONNEVELD C. 2001. Silicon in horticultural crops grown in soilless culture. In: DATNOFF LE; SNYDER GH; KORNDORFER GH (Eds). Silicon in Agriculture. London: Elsevier Science B.V. p.115-131.

ZONTA EP; MACHADO AA. 1984. SANEST Sistema de análise estatística para microcomputadores. Capinas: IAC - SEI $n^{\circ}$ 066060 . 